\title{
Spatial characteristics of aerosol physical properties over the northeastern parts of peninsular India
}

\author{
K. Niranjan ${ }^{1}$, B. Melleswara Rao ${ }^{1}$, P. S. Brahmanandam ${ }^{1}$, B. L. Madhavan ${ }^{1}$, V. Sreekanth ${ }^{1}$, and K. Krishna Moorthy ${ }^{2}$ \\ ${ }^{1}$ Department of Physics, Andhra University, Visakhapatnam 530 003, India \\ ${ }^{2}$ Space Physics Laboratory, Vikram Sarabhai Space Centre, Trivandrum 695 022, India
}

Received: 1 July 2005 - Revised: 14 September 2005 - Accepted: 20 September 2005 - Published: 30 November 2005

\begin{abstract}
Measurements on aerosol spectral optical depths and near surface mass-size distributions made at several locations in the states of Andhra Pradesh, Orissa and Chattisgarh, constituting the northeastern part of the peninsular India during the ISRO-GBP land campaign-I show significant regional variations in aerosol physical properties. Higher spectral optical depths were observed in the coastal regions and over southern latitudes compared to interior continental regions and northern latitudes. The optical depths, size index " $\alpha$ " and the near surface aerosol mass concentrations indicate a relative abundance of nucleation mode aerosols in the northern latitudes, in contrast to the dominance of the accumulation mode aerosols at the eastern coastal and southern latitudes. The airmass pathways derived from the back trajectory analysis indicate that the higher aerosol population in the accumulation mode, and consequently the higher optical depths in the southern locations, could be due to the transport of aerosol from the polluted north Indian regions via the oceanic region over the Bay of Bengal, where significant particle growth is expected, increasing the population of accumulation mode aerosols over these regions.
\end{abstract}

Keywords. Atmospheric composition and Chemistry (Aerosol and particles); Synoptic scale meteorology (Meteorology and atmospheric dynamics)

\section{Introduction}

Atmospheric aerosols result from various sources and processes that are highly variable in space and time. Ambient aerosols can directly modify the aerosol radiative forcing by backscattering and absorption. Aerosol particles are the largest sources of uncertainty in the current estimates of radiative forcing in terms of source strengths, lifetimes and transport. Efforts towards understanding the radiative effects of aerosols require a global aerosol particle assessment

Correspondence to: K. Niranjan

(niranjankandula@ hotmail.com) based on observation and have clearly demonstrated the need for in-situ and remote-sensing measurements at as many locations as possible, to generate atleast representative measurements of the large-scale phenomena. This will involve intercomparison of models, satellite-derived aerosol optical depths (AODs) and results from campaign-based measurements covering large areas. Besides the fundamental nature of aerosol phenomena, information on closely grided points is required to assess the effects of interpolation based on time/space averaging and also to evaluate the scaling distances over which the effect caused by the process subsides. The accuracy with which the aerosol radiative properties can be predicted depends on the measurement of aerosol physical, microphysical and chemical properties (Wang et al., 2002). A variety of sources, both natural and anthropogenic, and the short lifetimes of aerosols result in a spatially and temporally heterogeneous aerosol field, making aerosol characterization and modeling a real challenge (Smirnov et al., 2002). One of the recent advances in aerosol research is to make measurements over large areas, several thousands of kilometers, in order to assess the aerosol spatial variability over large geographical extents, which required ships, aircrafts, surface-based observations, and observations from mobile land platforms. Some field experiments have contributed to enhancing the understanding of aerosol physical properties and their role in regional and global radiative forcing; for example, TARFOX (Russell et al., 1999), the aerosol characterization experiment -I (Bates et al., 1998), the aerosol characterization experiment - II (Raes et al., 2000) and more recently, the INDOEX (Ramanathan et al., 2001). Though the satellite remote sensing of aerosol loading provides extensive spatial coverage, their inversion techniques need ground truth for their validation, which requires at least representative measurements at as closely spaced locations as possible.

It has been reported that the Asian continental outflow of air mass into the open ocean starts in November and continues up to April and, therefore, the regional distribution of aerosols over the Indian Ocean during this period is 


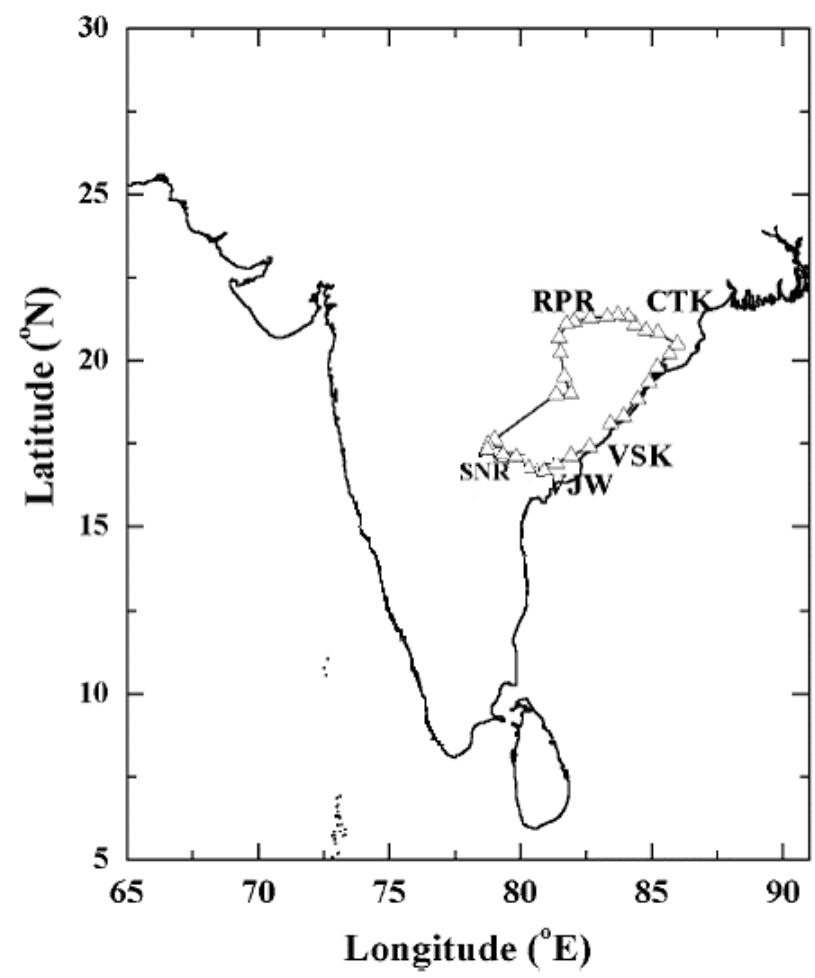

Fig. 1. Route taken by the Andhra University team in the ISROGBP Land Campaign. The triangles represent the locations of observation. The legends show major cities: VJW: Vijayawada, VSK: Visakhapatnam, CTK: Cuttack, RPR: Raipur, SNR, Shadnagar near Hyderabad.

substantially modified by the characteristics of the continental aerosol composition (Nair et al., 2003). Realizing the need for the characterization of the aerosol physical properties over the Indian sub-continent, an intensive field campaign was organized by the Indian Space Research Organization (ISRO) under the ISRO-Geosphere Biosphere Programme, named as the ISRO-GBP Land Campaign-I. Several research groups carried a host of instruments on mobile platforms and made representative measurements at several locations covering the entire peninsular India and a few meridional transects. The team from Andhra University, Visakhapatnam, India made extensive measurements of aerosol optical depths and near surface mass-size distributions along with the surface meteorological parameters at several locations in the states of Andhra Pradesh, Orissa and Chattsigarh, in the northeastern part of peninsular India. The features of aerosol spectral optical depths and near surface aerosol masssize distributions over this region are presented in this paper. The importance of the measurements in the regional aerosol transport into the Bay of Bengal is discussed.

\section{Observations and analysis}

Aerosol optical depth and the Ångström exponent are the work horses of Sun photometry, by which the optical state of
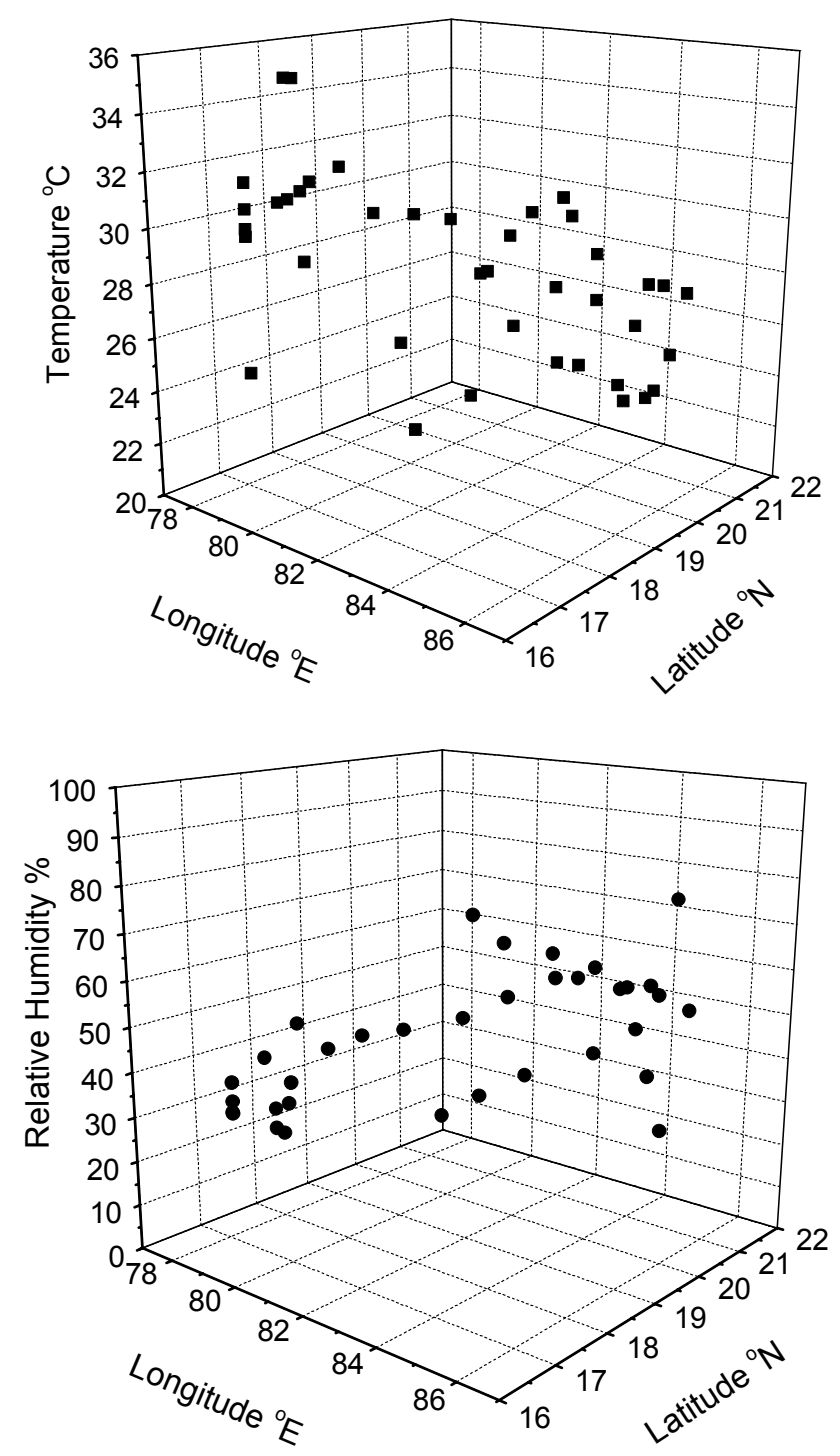

Fig. 2. Surface temperature (top panel) and humidity (bottom) at the observation sites.

the atmosphere can be assessed (O'Neill et al., 2003). Measurement of aerosol size distribution is also important for the study of aerosol impact on the climate system, because the effects are quite size dependant. With this view, extensive measurements of aerosol spectral optical depths and near surface aerosol mass-size distributions were made in the study region. Figure 1 shows the route followed by the team, and the triangles represent the locations (some locations were not shown to avoid overlapping of points) where aerosol measurements were made during 2-27 February 2004 . The route covered 37 locations with a latitude extent from $16.5^{\circ} \mathrm{N}$ to $21.5^{\circ} \mathrm{N}$, and the longitudinal coverage was from $78^{\circ} \mathrm{E}$ to $86.3^{\circ} \mathrm{E}$, over a distance of about $1500 \mathrm{~km}$. The spatial resolution between two adjacent measurements is approximately $50 \mathrm{~km}$. While making measurements it was ensured that the measurement location was not close to any strong anthropogenic activity (avoiding cities and major industries), so 


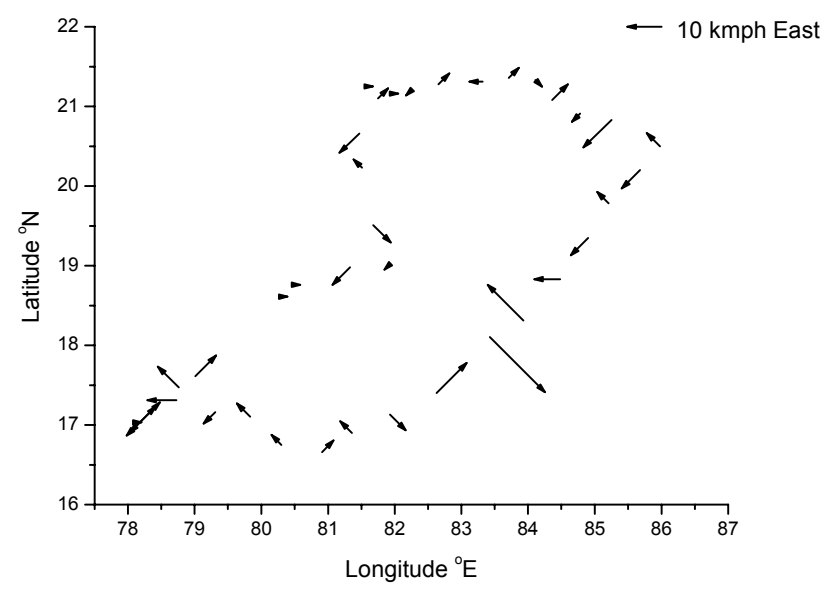

Fig. 3. Vector plot showing the wind speed and wind direction at the observing locations.

that the measurements represent the ambient air mass conditions in the study region. It was also ensured that the measurements were taken at least 4-5 km away from the national/state highways, so that the automobile emissions and dust were not sampled. The parameters measured were the aerosol spectral optical depths at 380, 440, 500, 675 and $870 \mathrm{~nm}$, using a Microtops II Sun photometer and near surface size segregated aerosol mass-size concentration in 10 channels, using California measurements Inc. Quartz Crystal Microbalance (QCM) with aerodynamic cutoff diameters in the range of 0.05 to $25 \mu \mathrm{m}$. The pump aspirates the ambient air at a flow rate of 0.24 liters per minute and is sampled for a duration of $300 \mathrm{~s}$. Each location is covered for half a day, and a set of at least four QCM samples at an interval of $30 \mathrm{~min}$ were collected, and the average with a standard deviation for each location was evaluated. The aerosol optical depth measurements were made at every 15 -min interval, with a minimum of eight observations for each location, and the mean AOD and the respective standard deviations were evaluated. Surface temperature, humidity, wind speed and wind direction were measured at all observational sites, along with the QCM observations, to characterize the air mass. The surface temperature at all the locations during the time of observation was between 21.8 to $30^{\circ} \mathrm{C}$ (Fig. 2 top panel), except at a couple of locations where it was around $35^{\circ} \mathrm{C}$ and the surface humidity was less than $60 \%$ at most of the locations (Fig. 2 bottom panel). The surface vector winds, shown in Fig. 3, were calm, with surface wind speeds less than $10 \mathrm{kmph}$, with different wind directions; the terrain was very uneven, and the surface wind speeds were showing different directions at different locations.

\section{Aerosol spectral optical depths}

Figure 4 shows the aerosol spectral optical depths at 500 and $870 \mathrm{~nm}$. The dot represents the coordinates of the location in latitude and longitude, and the length of the vertical bar
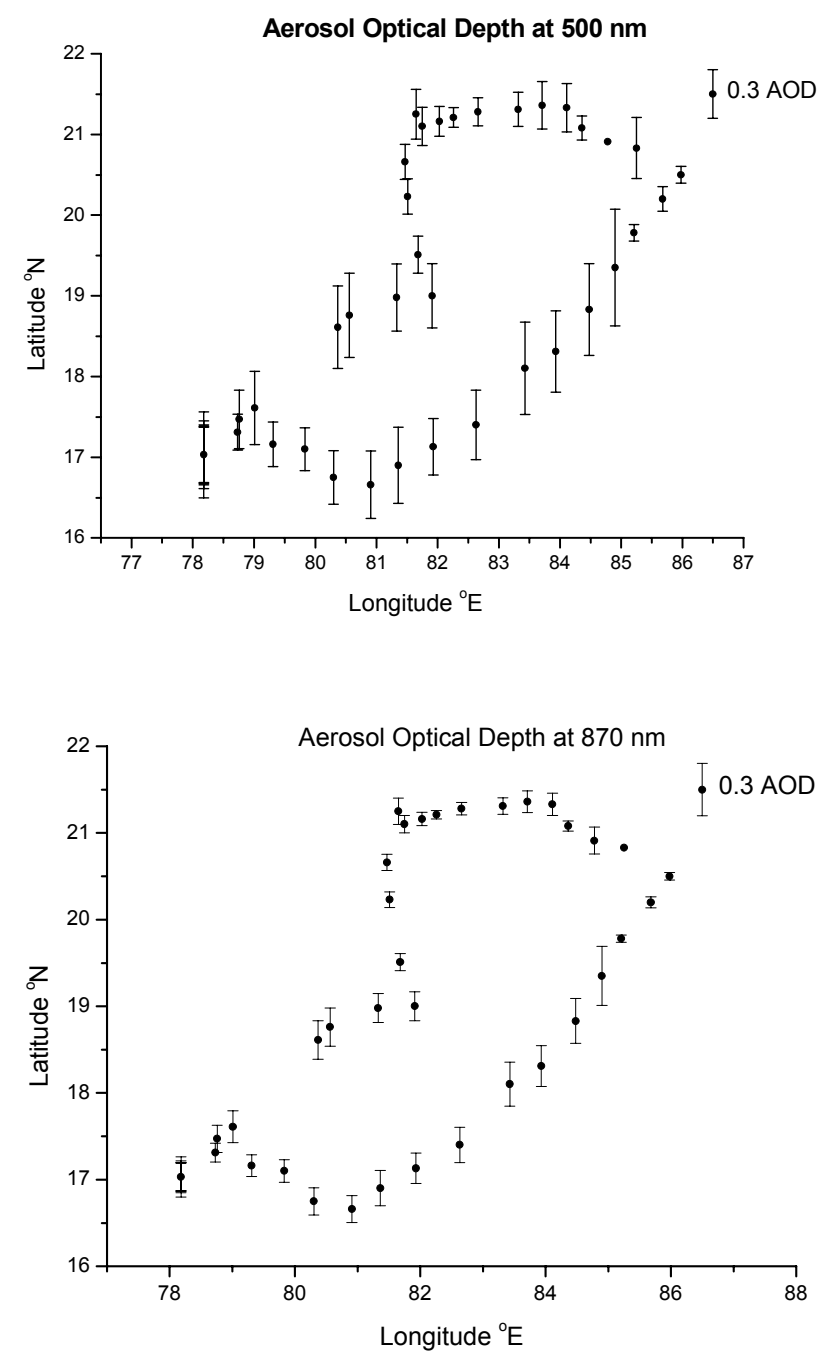

Fig. 4. Aerosol spectral optical depths at $500 \mathrm{~nm}$ (top panel) and $870 \mathrm{~nm}$ (bottom panel at different locations). The points represent the coordinates of the observations sites and the length of the vertical bar represents the magnitude of AOD.

represents the aerosol optical depth at the respective location. The vertical bar shown on the right top represents an aerosol optical depth of 0.3. In addition, subsequent figures, i.e. from Fig. 4 to Fig. 7, the length of the vertical bar represents the magnitude of the respective parameter, and the dots represent the co-ordinates of the observing location. It may be noticed from Fig. 4 that the aerosol optical depths are higher along the coastal locations on the East Coast. The aerosol optical depths decreased as we moved interior from the coast line and traveled towards Bhubaneswar (capital city of Orissa) and Cuttack, shown as CTK in Fig. 1. While traveling from east to west, from Cuttack to Raipur (shown as RPR in Fig. 1), the aerosol optical depths decreased as we moved away from Cuttack, which was having some industrial activity and again, the aerosol optical depths increased as we approached Raipur, the capital city of Chattisgarh, another urban location. In the north to south transect, from 


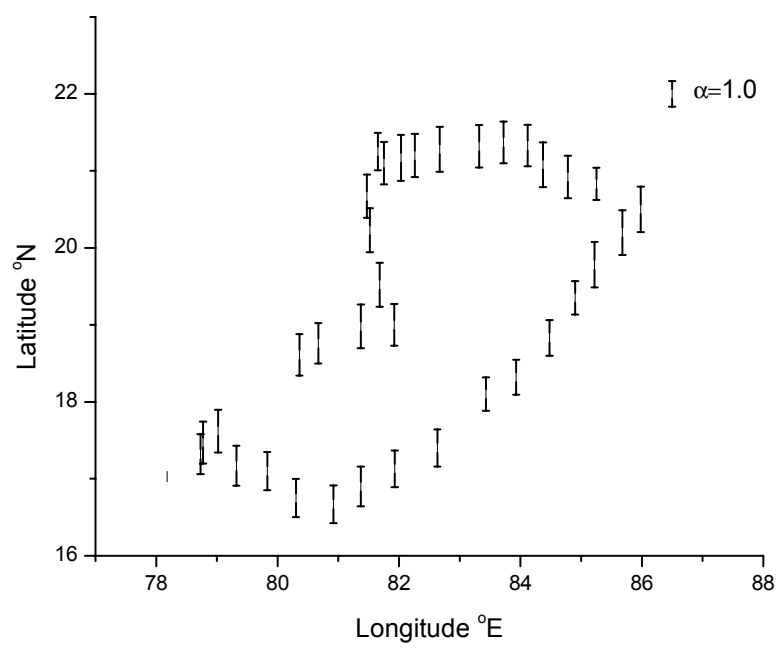

Fig. 5. Ångström parameter at $\alpha$ gt various observational sites derived from aerosol spectral optical depths.

Raipur to Shadnagar (SNR), near Hyderabad, the capital city of Andhra Pradesh, there was a decrease in aerosol optical depth in the down wind direction. But high aerosol optical depths were observed near the forest regions between $18^{\circ} \mathrm{N}$ to $19^{\circ} \mathrm{N}$ latitude. Measurements could not be made for about $150 \mathrm{~km}$ in the forest area, as the region was sensitive from a safety point of view. Again, in the transect from west to east, around $17^{\circ} \mathrm{N}$ latitude, the aerosol optical depths increased as we moved towards the coastal regions. The spectral optical depths at $870 \mathrm{~nm}$, shown in the bottom panel, also show similar features but were relatively smaller in magnitude. By and large the following gross features in aerosol optical depths were seen: a) the aerosol optical depths were higher on the eastern side compared to the central part of the peninsular India b) the optical depths were relatively higher in the southern latitudes compared to northern latitudes, and c) there were some locations where very low AODs, of the order of 0.1 , were observed, which happened to be extremely rural locations devoid of any major anthropogenic activity.

The spectral slope, " $\alpha$ ", and the turbidity coefficient, " $\beta$ ", are the two important parameters that characterize the shape of the aerosol size distribution. The Ångström parameters ( $\alpha$ and $\beta$ ) at the observed locations were evaluated from the spectral optical depths at 5 wavelengths, and Fig. 5 shows the spectral slope " $\alpha$ " which was found to be in the range of 1.3 to 1.8 at most of the locations, indicating the presence of anthropogenic aerosols at most of the locations. While a high value of spectral slope " $\alpha$ " indicates the dominance of fine mode aerosols, a high turbidity coefficient " $\beta$ " indicates higher aerosol loading. It was observed that the mean value of " $\alpha$ " was 1.3 in the eastern and southern locations compared to a mean of 1.76 in the northern and western locations. High values of " $\alpha$ " are characteristic of an urban environment, which could be seen near Bhubaneswar/Cuttack and downwind of Visakhapatnam, a major coastal industrial city (Niranjan et al., 2004). It was also observed that the val-
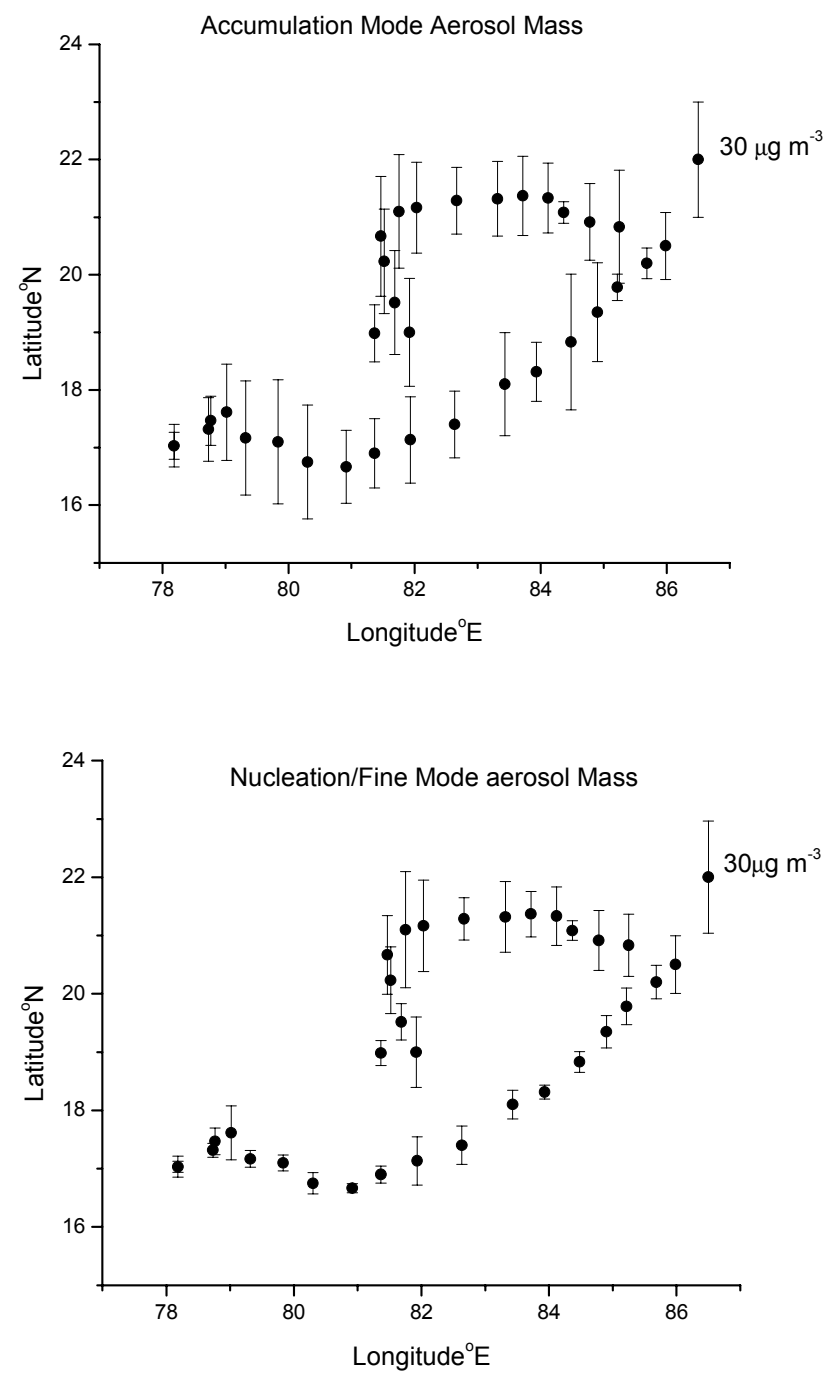

Fig. 6. Accumulation (top panel) and nucleation (bottom panel) mode aerosol mass concentrations derived from QCM data at the observational sites.

ues of " $\beta$ " are higher on the southern and eastern locations, with relatively low values of " $\alpha$ " compared to the northern and western locations, as observed in the 500-nm aerosol optical depths.

\section{Near surface aerosol mass concentrations}

The QCM derived aerosol mass concentrations during the campaign that covered the major part of the peninsular India indicate comparatively high aerosol concentrations along the east coastal regions and locations close to the urban areas (Moorthy et al., 2005). In Fig. 6 the accumulation mode (geometric mean radius between 0.1 and $1 \mu \mathrm{m}$ ) and nucleation/fine mode (geometric mean radius $<0.1 \mu \mathrm{m}$ ) are shown for aerosol mass concentrations evaluated from the size segregated aerosol mass concentrations in the different channels of the QCM measurement. The nucleation mode 


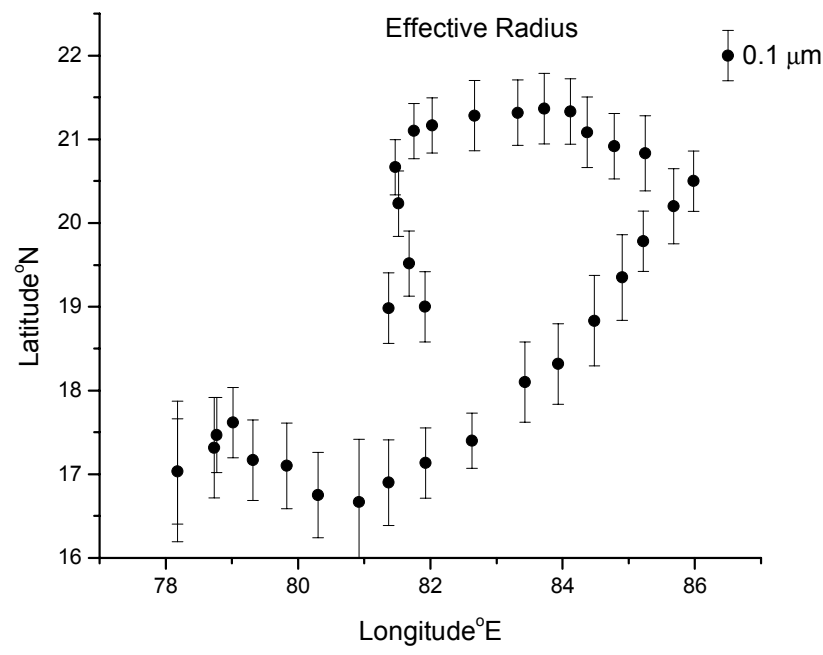

Fig. 7. Effective radii derived from QCM data for the observation sites.

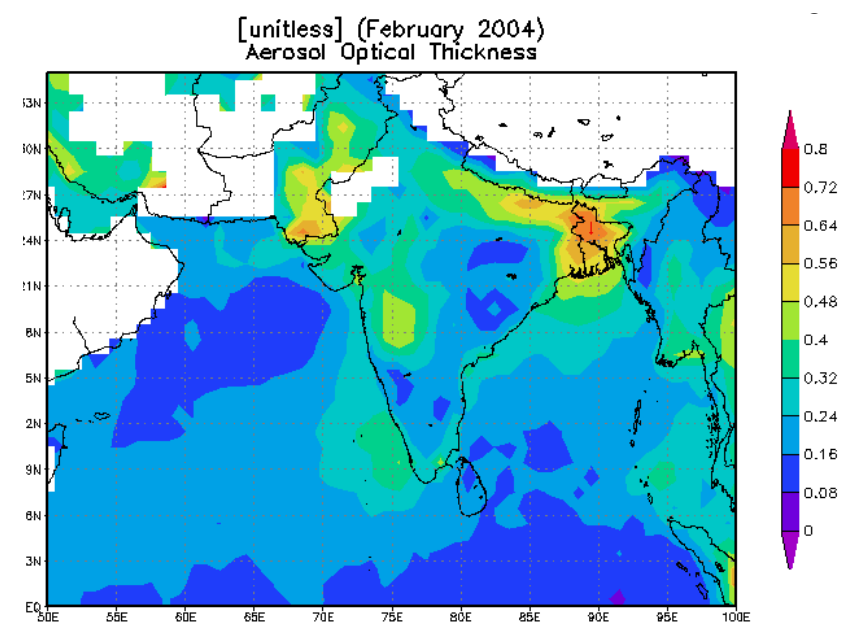

Fig. 8. MODIS derived map of aerosol optical thickness showing region of high pollution over northern India that is entering the Bay of Bengal oceanic region through northeastern India.

concentrations were high in the northern latitudes while the accumulation mode concentrations were relatively higher in the eastern and southern latitudes. The high nucleation mode aerosol indicates the dominance of nascent and relatively younger aerosol, characteristic of anthropogenic origin while the accumulation aerosol indicates aged aerosol, which could partly be transported from nonlocal sources.

The effective radius indicates the equivalent monodispersion radius that can exhibit equivalent total optical scattering characteristics as a polydispersion system, or otherwise defined as the ratio of total volume to total surface area (McCartney, 1976). From the QCM mass concentration measured in each size bin, the corresponding volume and area are estimated from which the effective radius is evaluated following the method suggested by Moorthy et al., (2003a) and presented in Fig. 7. It may be noticed that the effective radii

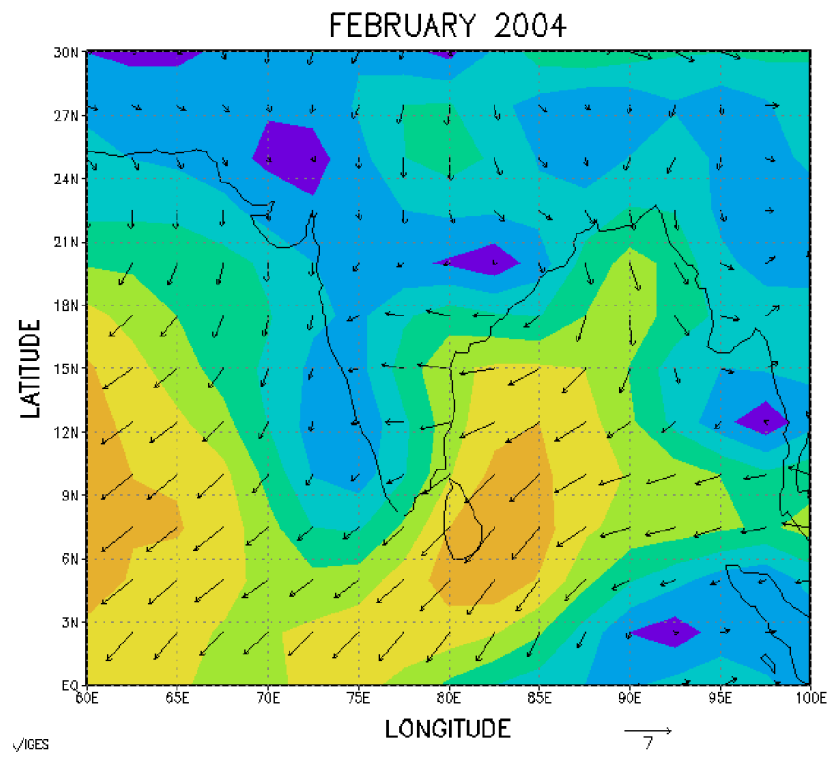

Fig. 9. Mean isotachs $\left(\mathrm{ms}^{-1}\right)$ at $850 \mathrm{~h} \mathrm{~Pa}$ level over peninsular India for February 2004 obtained from NCEP/NCAR reanalysis.

are relatively larger for the eastern and southern locations compared to the northern and western locations, indicating the abundance of relatively large particle concentrations in the eastern and southern locations compared to the northern and western locations.

\section{Discussion}

Aerosol physical properties at a given location are largely governed by the local processes that lead to aerosol formation, which are modified by the prevailing weather and interaction with air mass advection, besides transport of aerosol from sources of nonlocal origin. Marine aerosols produced in the surf zone at high concentrations are immediately available for heterogeneous chemical reactions and influence the composition of aerosols at coastal locations (Vignati et al., 2001). Thus, the aerosol physical properties at coastal locations significantly differ from those observed at deep continental locations. In addition, large-scale transport of aerosols from dry continental regions significantly modify the aerosol radiative forcing over oceanic regions (Meywerk and Ramanathan, 1999; Nair et al., 2003; Franke et al., 2003). Thus, at coastal locations either on land or in the ocean, the aerosols exhibit complex physical properties due to the interaction of the continental and marine air masses (Niranjan et al., 2004). In the present investigation, it is observed that the coastal locations indicate high aerosol optical depths and low values of the Ångström exponent, as well as high near surface mass concentrations of accumulation mode aerosols. At coastal locations, the marine boundary layer penetrates inland, bringing in humid airmass, which contains some sea salt aerosol from the marine boundary layer. In addition, the humid airmass from the oceanic region interacts with the continental 

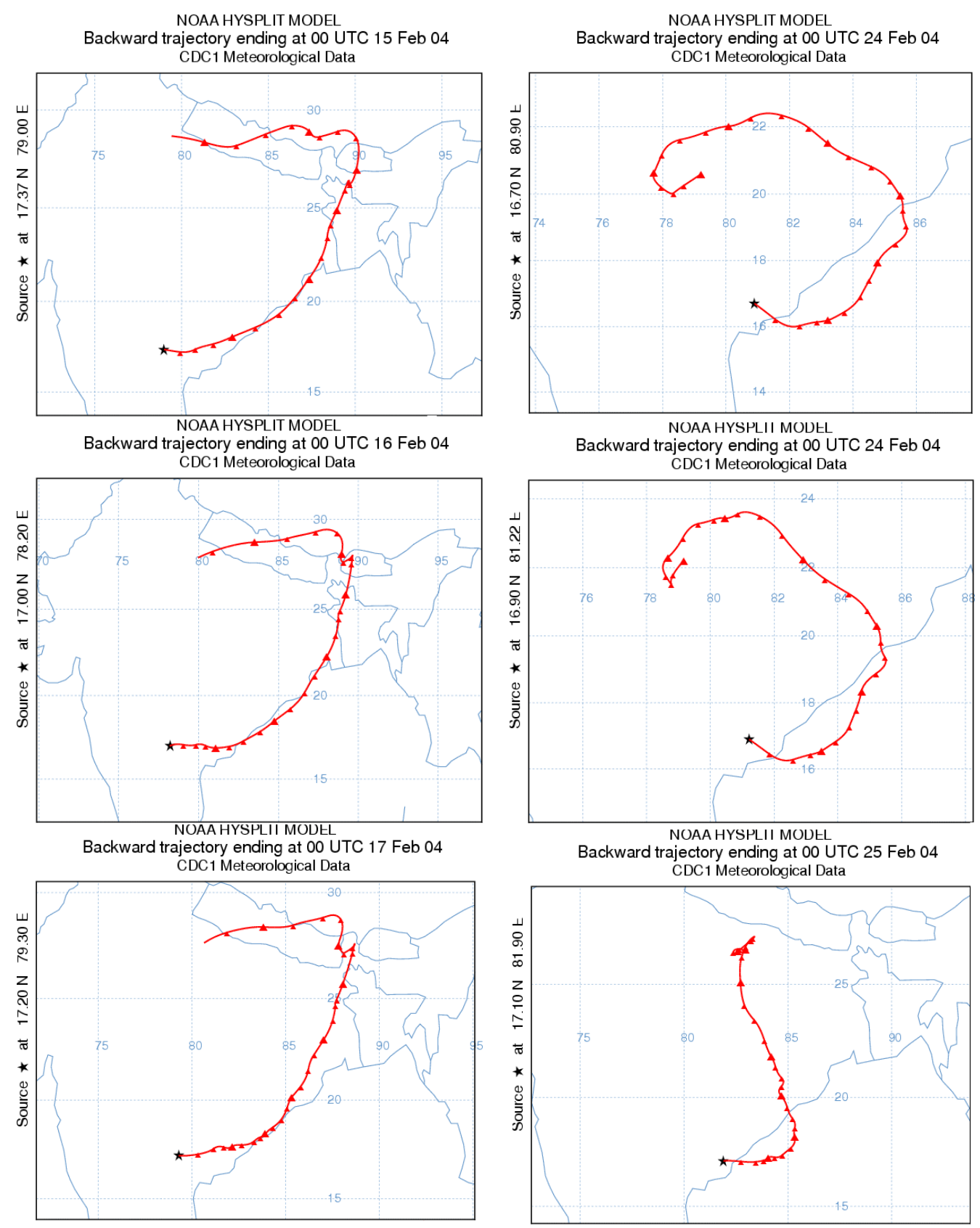

Fig. 10. Back trajectories for six typical cases with source locations at the southern observations sites for the respective day of observation produced with HYSPLIT from NOAA ARL web site.

airmass, making conditions favorable for growth of hygroscopic aerosols, as well as for the formation of new particles by condensation and nucleation by gas-to-particle conversion from the precursors emitted from the continents due to anthropogenic activity. Thus, coastal regions show higher aerosol optical depths and mass concentrations.

One of the significant features observed in the present study is the high aerosol optical depth at southern locations in the latitudinal belt around $17^{\circ} \mathrm{N}$ compared to the northern locations around $21^{\circ} \mathrm{N}$. It has been reported that there is a transport of aerosols from the northern and central Indian regions to peninsular India and oceanic regions. Figure 8 shows the MODIS derived aerosol optical thickness for the month of February over the Indian region. A region of high pollution is seen in the northern and central India, which enters the Bay of Bengal region, increasing the aerosol concentrations over the Bay of Bengal. Figure 9 shows the mean winds at $850 \mathrm{hPa}$ obtained from the National Centre for Environmental Prediction/National Centre for Atmospheric Research reanalysis. It may be noticed that the winds carry the highly polluted airmass from the northen India into the Bay of Bengal and streamlines re-enter the peninsular Indian 

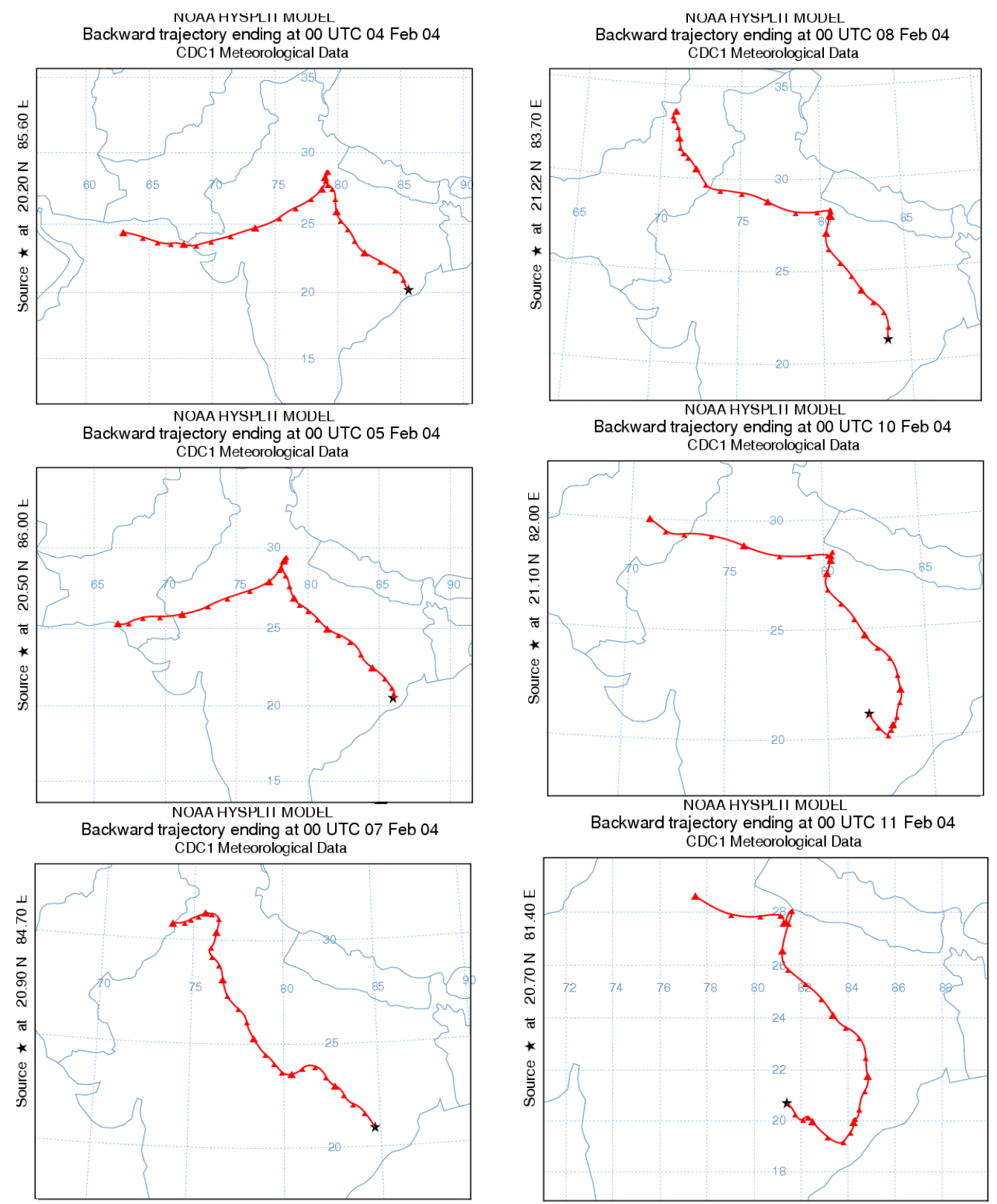

Fig. 11. Same as Fig. 10 for northern observation sites.

around $17-18^{\circ} \mathrm{N}$ latitude. The airmass pathways reported by Nair et al. (2003) also show similar trajectories during February 1999 , with streamlines at $850 \mathrm{hPa}$ re-entering the peninsular India around $18^{\circ} \mathrm{N}$. Satheesh et al. (1999) reported that the major features affecting the aerosol characteristics over the tropical Indian Ocean during the northeast monsoon season are the transport of pollutants from the Asian sub-continent and to a lesser extent humidity, as direct production at the sea surface is not efficient due to low wind speeds. The non-sea salt AOD was more than 3 times the sea salt aerosol in the Indian Ocean (Rajeev et al., 2000). The aerosol loading over the Bay of Bengal is significantly influenced by aerosol transport from the Indian sub-continent and the AODs increase by a factor of 1.7 from November to April (Nair et al., 2003). Satheesh (2002) reported that the aerosol visible optical depths over the Bay of Bengal are as high as 0.6 and that the aerosol radiative forcing was high compared to other oceans, such as Pacific, Atlantic, Arabian Sea and Indian Ocean. Aerosol measurements made at an island station Port Blair in the Bay of Bengal show a continental type of aerosol with an AOD of 0.3 to 0.4 at $500 \mathrm{~nm}$ (Moorthy et al., 2003b). The airmass passing through the highly polluted north Indian regions during winter traverses over the Bay of Bengal, interacts with the marine boundary layer and the modified airmass re-enters the sub-continent and travels across the peninsular India at latitudes south of 
$18^{\circ} \mathrm{N}$. During this transit over the ocean, sub-micro meter particles grow in the marine boundary layer by homogeneous and heterogeneous mechanisms and the majority of the accumulation mode aerosols in such cases are certainly produced in the marine boundary layer (Covert et al., 1996).

Figure 10 shows the seven day back trajectories at $500 \mathrm{~m}$ altitude for a given atmospheric level taken from the NOAA HYSPLIT model for six typical locations in the southern latitudes with source point and time at the location of observation. Figure 11 shows similar plots for six typical northern locations. It may be seen that the back trajectories show that the airmass movement over the northern observational sites around $21^{\circ} \mathrm{N}$ was from northern India, which is expected to bring the polluted airmass directly from the continent over the observing locations. Thus, these locations show higher concentrations of sub-micro meter/fine mode aerosols characteristic of urban transport. As the prevailing weather condition is dry, no significant particle growth takes place and the AODs are governed by the scaling distance of the location from the north Indian high pollution region and the terrain characteristics encountered in the airmass pathways besides the contributions from local sources. This is true for $90 \%$ of the cases in the present study of the back trajectories.

In contrast, when observations were made at locations around $16-17^{\circ} \mathrm{N}$, the airmass flow from the northern India is via the Bay of Bengal oceanic region or the coastal regions and then on to the observing locations, after re-entry into the peninsular India. Thus significant particle growth takes place during the travel over the oceanic/coastal regions, leading to an increase in the accumulation mode particle concentration. However, during the transit, considerable increase in the sea salt component does not take place due to low wind speeds and hence the super micro-meter aerosol concentration is not significantly increased. Thus, high AODs with relatively lower values of " $\alpha$ ", higher concentrations of accumulation mode aerosols and lower concentrations of nucleation/fine mode aerosols are seen at locations south of $17-18^{\circ} \mathrm{N}$ latitudes.

\section{Summary}

Aerosol spectral optical depths and near surface size segregated mass distributions measured in the northeastern part of peninsular India indicate that the aerosol spectral optical depths and accumulation mode aerosol concentrations are high in the eastern coastal and southern regions (latitudes less than $17-18^{\circ} \mathrm{N}$ ) compared to northern regions (latitudes more than $20^{\circ} \mathrm{N}$ ) and deep continental locations. The coastal locations are thought to be affected by the proximity of the marine airmass and consequent hygroscopic growth of particles, besides new particle formation by condensation and nucleation, showing higher aerosol optical depths. The airmass trajectories and general wind patterns indicate that an abundance of accumulation mode aerosols is possible at the southern locations, as the airmass pathways through which transport of north Indian polluted airmass onto the locations of observation at southern latitudes takes place via the oceanic regions of the Bay of Bengal, making conditions favorable for the increase in the accumulation mode aerosols.

Acknowledgements. This work was carried out under the ISROGBP land campaign-I with financial support from ISRO-GBP. The authors thank Shyam Lal, the campaign co-ordinator for the support and encouragement. The NCEP/NCAR reanalysis is provided by the NOAA-CIRES climate diagnostic centre, Boulder, Colorado. The back trajectories were produced with HYSPLIT from the NOAA ARL website http://www.arl.noaa.gov/ready/. The monthly mean aerosol optical thickness map of February 2004 shown in Fig. 8 is obtained from MODIS web site. The authors thank the reviewers for their suggestions.

Topical Editor F. D'Andréa thanks N. Laulainen and another referee for their help in evaluating this paper.

\section{References}

Bates, T. S., Heubert, B. J., Gras, J. L., Griffiths, F. B., and Durkee, P. A.: International Global atmospheric chemistry (IGAC) project's first Aerosol Characterization Experiment: Overview, J. Geophys. Res., 103, 16 297-16318, 1998.

Covert, D. S., Kapustin, V. N., Bates, T. S., and Quinn, P. K.: Physical properties of marine boundary layer aerosol particles of the mid-Pacific in relation to sources and meteorological transport, J. Geophys.Res., 101, 6919-6930, 1996.

Franke, K., Ansmann, A., Muller, D., Althausen, D., Venkataramn, C., Shekar Reddy, M., Wagner, F., and Scheele, R.: Optical properties of the Indo-Asian haze layer over the tropical Indian Ocean, J. Geophys. Res., 108, D2, 4059, doi:10.109/2002JD002473, 2003.

McCartney, E. J.: Optics of the Atmosphere, John Wiley, New York, 135-136, 1976.

Meywerk, J. and Ramanathan, V.: Observations of the spectral clear-sky aerosol forcing over the tropical Indian Ocean, J. Geophys. Res., 104, 24 359-24 370, 1999.

Moorthy, K. K., Sunil Kumar, S. V., Pillai, P. S., Parameswaran, K., Nail, P. R., Nazeer Ahmed, Y., Ramgopal, K., Narasimhulu, K., Reddy, R. R., Vinoj, V., Satheesh, S. K., Niranjan, K., Rao, B. M., Brahmanandam, P. S., Saha, A., Badarinath, K. V. S., Kiranchand, T. R., and Madhavi Latha, K.: Wintertime spatial characteristics of boundary layer aerosols over peninsular India, J. Geophys. Res., 110, D08207, doi:1029/2004JD005520, 2005.

Moorthy, K. K., Pillai, P. S., and Suresh Babu, S.: Influence of changes in the prevailing synoptic conditions on the response of aerosol characteristics to Land and Sea breeze circulations at a coastal station, Boundary layer Meteorology, 108, 145-161, 2003a.

Moorthy, K. K., Suresh Babu, S., and Satheesh, S. K.: Aerosol spectral optical depths over Bay of Bengal: Role of transport, Geophys. Res. Lett., 30, 1249, doi:10.1029/2002GL016520, 2003b.

Nair, S. K., Rajeev, K., and Parameswaran, K.: Wintertime regional aerosol distribution and the influence of continental transport over the Indian Ocean, J. Atmos., Solar Terr. Phys., 656, 149165, 2003.

Niranjan, K., Malleswara Rao, B., Saha, A., and Murthy, K. S. R.: Aerosol spectral optical depths and size characteristics at a coastal industrial location in India-effect of synoptic and mesoscale weather, Ann. Geophys., 22, 1851-1860, 2004,

SRef-ID: 1432-0576/ag/2004-22-1851. 
O’Neill, N. T., Eck, T. F., Smirnov, A., Holben, B. N., and Thulasiraman, S.: Spectral discrimination of coarse and fine mode optical depths, J. Geophys.Res., 108, D(17),4559, doi:10.1029/2002JD002975, 2003.

Raes, F., Bates,T., Mc Govern, F., and Liedekerke, M. V.: The 2nd Aerosol Characterization Experiment (ACE-2): general overview and main results, Tellus, Ser B, 52, 111-125, 2000.

Rajeev, K., Ramanathan, V., and Meywerk, J.: Regional aerosol distribution and its long-range transport over the Indian Ocean, J. Geophys. Res., 105, 2029-2043, 2000.

Ramanathan, V., Crutzen, P. J., Lelieveld, J., Mitra, A. P., Althausen, D., Anderson, J., Andreae, M. O., Cantrell, W., Cass, G. R., Chung, C. E., Clarke, A. D., Coakley, J. A., Collins, W. D., Conant, W. C., Dulac, F., Heintzenberg, J., Heymsfield, A. J., Holben, B., Howell, S., Hudson, J., Jayaraman, A., Kiehl, J. T., Krishnamurti, T. N., Lubin, D., McFarquhar, G., Novakov, T., Ogren, J. A., Podgorny, I. A., Prather, K., Priestley, K., Prospero, J. M., Quinn, P. K., Rajeev, K., Rasch, P., Rupert, S., Sadourny, R., Satheesh, S. K., Shaw, G. E., Sheridan, P., and Valero, F. P. J.: The Indian Ocean Experiment: An integrated analysis of the climate forcing and effects of the great Indo-Asian haze, J. Geophys. Res., 106, 28 371-28 398, 2001.

Russell, B. P., Hobbs, P. V., and Stove, L. L.: Aerosol properties and radiative effect in the United states east coast haze plume: an overview of Tropospheric Aerosol Radiative Forcing Observational Experiment (TARFOX), J. Geophys. Res., 104, 2213$2222,1999$.
Satheesh, S. K., Ramanathan, V., Li-Jones, X., Lobert, J.M., Podgorny, I. A., Prospero, J. M., Holben, B. N., and Loeb, N. G.: A model for the natural and anthropogenic aerosols over tropical Indian Ocean derived from Indian Ocean Experiment data, J. Geophys. Res., 104, 27 421-27 440, 1999.

Satheesh, S. K.: Radiative forcing by aerosols over Bay of Bengal region, Geophys. Res. Lett., 29, 2083, doi:10.1029/2002GL015332, 2002.

Smirnov, A., Holben, B. N., Kaufman, Y. J., Dubovik, O., Eck, T. F., Slutsker, I., Paitras, C., and Halthore, R. N.: Optical properties of atmospheric aerosol in maritime environments, J. Atmos., Sci., 59, 501-523, 2002.

Vignati, E., de Leeuw, G., and Berkowicz, R.: Modeling coastal aerosol transport and effects of surf produced aerosols on process in the marine boundary layer, J. Geophys. Res., 106, 20225$20238,2001$.

Wang, J., Flagan, R. C., Seinfeld, J. H., Jonsson, H. H., Collins, D. R., Russell, P. B., Schmid, B., Redemann, J., Livingston, J. M., Gao, S., Hegg, D. A., Welton, E. J., and Bates, D.: Clear-column radiative closure during ACE-Asia: Comparison of Multiwavelength extinction derived from particle size and composition with results from Sun photometry, J. Geophys.Res., 107(D23),4688, doi:10.1029/002JD002465, 2002. 